\title{
DUGOROČNA ANALIZA UČINKA PLAĆA U JAVNOM SEKTORU NA EKONOMSKU AKTIVNOST U HRVATSKOJ ${ }^{* * *}$
}

Plaće u javnom sektoru bitan su dio državnog proračuna te su značajan element vođenja fiskalne politike. Svrha ovog istraživanja je empirijski ispitati kako plaće u javnom sektoru utječu na ekonomsku aktivnost u maloj otvorenoj ekonomiji na primjeru Hrvatske. S obzirom na rezultate prethodnih empirijskih istraživanja, postavljena je istraživačka hipoteza prema kojoj porast javnih plaća u Hrvatskoj dovodi do smanjenja ekonomske aktivnosti. U središnjem dijelu rada dugoročni učinak javnih plaća na ekonomska kretanja u Hrvatskoj ispitan je primjenom Johansenovog pristupa kointegraciji, pri čemu su korišteni mjesečni podaci o plaćama u javnom sektoru i indeksima industrijske proizvodnje od siječnja 2000. do veljače 2017. godine. Rezultati provedenog istraživanja upućuju na to da porast javnih plaća u dugom roku uzrokuje smanjenje ekonomske aktivnosti u Hrvatskoj, što je u skladu s prethodnim istraživanjima u inozemnoj literaturi. Rezultati istraživanja upućuju na potrebu provođenja fiskalne konsolidacije u većoj mjeri putem smanjenja javnih rashoda, u koje su uključene i javne plaće, a manje porastom poreznog opterećenja.

Ključne riječi: plaće u javnom sektoru, ekonomska kretanja, model korekcije pogreške, Johansenov pristup kointegraciji, mala otvorena ekonomija

* Dr. sc. I. Palić, docentica, Sveučilište u Zagrebu, Ekonomski fakultet Zagreb (E-mail: ipalic@efzg.hr).

${ }^{* *}$ B. Krizel, studentica, Sveučilište u Zagrebu, Ekonomski fakultet Zagreb (E-mail: barbarakrizel@gmail.com).

Rad je primljen u uredništvo 29.09.2017. godine, a prihvaćen je za objavu 08.02.2018.

*** Ovaj rad je podržan od strane Hrvatske zaklade za znanost kao dio znanstvenog projekta „Statistical Modelling for Response to Crisis and Economic Growth in Western Balkan Countries“ (STRENGTHS); broj projekta: 9402. 


\section{Uvod}

Analiza učinka plaća u javnom sektoru na gospodarstvo u posljednjih nekoliko desetljeća često je predmet ekonomskih istraživanja. Usto što su javne plaće važan dio državnog proračuna, te time i bitan element vođenja fiskalne politike svake zemlje, plaće u javnom sektoru imaju značajnu ulogu na tržištu rada (Afonso i Gomez, 2010.). Svjetska financijska i gospodarska kriza koja je započela u SAD-u 2007. godine, dodatno je ukazala na važnost istraživanja učinka plaća u javnom sektoru. Mogući razlog tome je porast proračunskih deficita i javnog duga, pri čemu je fiskalna konsolidacija postala nužna za njihovo smanjenje. Uslijed povećane potrebe za fiskalnom konsolidacijom i makroekonomskim oporavkom u mnogim se radovima analiziraju učinci promjene plaća u javnom sektoru na cjelokupno gospodarstvo, odnosno na ekonomski rast koji bi mogao dovesti do smanjenja povećanih deficita i javnog duga.

Cilj ovog rada je empirijski ispitati učinak javnih plaća u Hrvatskoj na ekonomska kretanja. Prije svega potrebno je istaknuti da je Hrvatska mala otvorena ekonomija. Mala otvorena ekonomija u literaturi se definira kao zemlja koja nema utjecaja na kretanja na inozemnim tržištima, odnosno na inozemnim tržištima nije značajan konkurent i cijene uzima kao zadane (Rodseth, 2000.). Slično, i Galì (2008.) malu otvorenu ekonomiju definira kao ekonomiju koja nema utjecaja na svjetska kretanja, ali je izložena utjecajima stranog sektora. U radu je primjenom Johansenovog pristupa kointegraciji i procjenom vektorskog modela korekcije pogreške (engl.vector error correction, VEC) provedena analiza učinka javnih plaća na ekonomska kretanja u razdoblju od siječnja 2000. do veljače 2017. godine. Učinak javnih plaća na ekonomske uvjete nije prethodno empirijski istražen u hrvatskoj literaturi primjenom ekonometrijskog modeliranja. Ovo istraživanje prvi puta provodi ekonometrijsku analizu učinka javnih plaća na hrvatsko gospodarstvo, što upućuje na važan znanstveni doprinos provedenog istraživanja. Analizom učinka javnih plaća provedeno istraživanje ponudit će smjernice za nositelje fiskalne politike, budući da su javne plaće bitan element vođenja fiskalne politike. U nastavku je dan pregled relevantnih istraživanja, koji ukazuje kako većina empirijskih istraživanja u inozemnoj literaturi ukazuje na to veći državni rashodi i javne plaće negativno utječu na ekonomski rast. Uzimajući u obzir prethodna istraživanja postavljena je istraživačka hipoteza prema kojoj porast javnih plaća u Hrvatskoj dovodi do smanjenja ekonomske aktivnosti. 


\section{Pregled dosadašnjih istraživanja}

Istraživanja u kojima se analiziraju čimbenici koji utječu na ekonomski rast su brojna, pri čemu se nastoji ispitati koji sve čimbenici i na koji način dovode do razlika u ekonomskoj razvijenosti i stopama rasta među zemljama. Pritom sve važniju ulogu u takvim istraživanjima dobiva javni sektor. Većina istraživanja učinka državne potrošnje, u koju su uključene i plaće u javnom sektoru, na ekonomski rast pokazuje negativan učinak. Sever et al. (2011.) istražuju odnos državnih rashoda i djelovanja na rast i strukturu BDP-a u Hrvatskoj. Primjenom modela vektorske autoregresije zaključuju da je struktura javnih rashoda ključna za djelovanje proračunske potrošnje na ekonomski rast, odnosno pokazuju da nepovoljni utjecaj proračunske potrošnje na ekonomski rast proizlazi iz neadekvatne strukture, gdje najveći dio izdataka čine naknada za zaposlene i socijalne naknade. Herath (2010.) dolazi do istih rezultata na primjeru Šri Lanke. Koristeći deskriptivnu statističku analizu promatra državne rashode, investicije i ekonomski rast. Dolazi do zaključka da su prekomjerni državni rashodi negativno povezani s gospodarskim rastom, dok postoji pozitivna veza između investicija i gospodarskog rasta. Nadalje, Zimčík (2016.) pomoću regresijskog panel modela promatra utjecaje različitih poreza i državnih rashoda na ekonomski rast u 20 zemalja Europske unije od 1995. do 2012. godine. Dolazi do zaključaka sukladnih prethodno navedenim istraživanjima, odnosno ukazuje na to da povećanje državnih rashoda ima negativan utjecaj na ekonomski rast. Naglašava da nagomilani deficiti i akumulacija duga u promatranom razdoblju zahtijevaju fiskalno zaoštravanje.

Međutim, Pascual Sáez et al. (2017.) smatraju da odnos između ekonomskog rasta i državnih rashoda može biti pozitivan i negativan, ovisno o zemljama uključenih u uzorak, razdoblju procjene i varijablama koje odražavaju veličinu javnog sektora. Promatrajući zemlje Europske unije za razdoblje od 1994. do 2012. pomoću regresijskog panel modela dolaze do zaključka da je taj odnos pozitivan za Portugal i Ujedinjeno kraljevstvo, dok je on negativan za Austriju, Finsku, Italiju i Švedsku te nesignifikantan za Belgiju, Francusku, Grčku, Irsku, Nizozemsku i Španjolsku. No, gledajući europske zemlje u cjelini, ipak smatraju da je spomenuti odnos negativan.

Trošt i Bojnec (2015.) analiziraju povezanost između izvoza, ekonomskog rasta i plaća u javnom sektoru u Sloveniji primjenom Johansenovog pristupa kointegraciji. Kao važnu komponentu fiskalne konsolidacije navode konsolidaciju javnih rashoda za postizanje stabilnog rasta, odnosno smatraju da će takva konsolidacija biti manje štetna i učinkovitija od konsolidacije temeljene na porastu poreza (Alesina i Ardagna, 1998.; Ardagna, 2004.). Navedeno su empirijski dokazali, zaključivši da potrošnja države na javne plaće ima negativan velik učinak na slovensku gospodarsku aktivnost. 
Slično prethodnome istraživanju, Hernández de Cos i Moral-Benito (2014.) naglašavaju važnost dizajna mjera fiskalne konsolidacije za makroekonomski oporavak. Stoga je identifikacija mjera konsolidacije koje potiču rast ključni izazov za kreatore fiskalne politike. Kroz istraživanje koristili su Bayesovu teoriju odlučivanja i regresijski panel model, a kao ključnu komponentu uspješne politike u spomenutom radu navedene su plaće u javnom sektoru, pri čemu autori smatraju da je smanjenje javnih plaća i/ili smanjenje broja zaposlenih u javnom sektoru najsnažnija odrednica uspješne financijske konsolidacije.

Nadalje, Holm-Hadulla et al. (2010.) istražuju ulogu vladinih plaća kao odrednice makroekonomske stabilnosti i konkurentnosti u eurozoni pomoću VAR modela, te zaključuju da su rashodi za plaće u javnom sektoru podložni procikličkom kretanju tj. podudaraju se s poslovnim ciklusima u većini zemalja eurozone. Dakle, spomenuti rashodi mogu pojačati, a ne ublažiti fluktuacije u gospodarskoj aktivnosti. U spomenutom radu analizira se odnos privatnih i javnih plaća i dokazuje se snažna pozitivna korelacija u kratkom i srednjem roku, izravno i neizravno preko razine cijena. U nekim zemljama je taj odnos rezultirao jakim porastom javnih plaća i gubitkom konkurentnosti unutar eurozone.

Međutim, suprotno gore navedenim istraživanjima, Callan et al. (2010.) korištenjem modela simulacije učinka poreza analiziraju kako su plaće u javnom sektoru u Irskoj reagirale na krizu, te ukazuju na to da su se plaće u javnom sektoru smanjile kao odgovor na gospodarsku krizu. Međutim, autori naglašavaju da srednjoročno i dugoročno one trebaju biti dovoljne za privlačenje i zadržavanje pojedinaca s kvalifikacijama i vještinama potrebnima za pružanje kvalitetnih javnih usluga. Također, tu je potrebno napomenuti da je u spomenutom istraživanju korištena simulacija, za razliku od ostalih analiziranih radova u kojima su korišteni ekonometrijski modeli procijenjeni korištenjem stvarnih podataka. Uz taj rad, Caponi (2017.) smatra kako zapošljavanje u javnom sektoru djeluju kao stabilizator. Ukazuje na to da bi one politike koje povećavaju zapošljavanje u javnom sektoru trebale biti praćene politikama određivanja plaća koje omogućuju da plaće budu što je moguće više fleksibilne u odnosu na produktivnost. Prema spomenutom istraživanju, kada javne plaće reagiraju na produktivnost i usklađuju se s privatnim plaćama, veličina javnog zaposlenja djeluje kao automatski stabilizator koji smanjuje fluktuacije nezaposlenosti tijekom poslovnog ciklusa.

Nadalje, Algan et al. (2001.) i Afonso i Gomes (2010.) su uglavnom usmjereni na analizu broja zaposlenih i plaća u javnom sektoru u odnosu na privatni sektor. Oba spomenuta istraživanja naglašavaju ulogu plaća u javnom sektoru na tržištu rada, odnosno ukazuju na to da plaće i zaposlenost u javnom sektoru utječu na plaće privatnog sektora kroz dva kanala. S jedne strane, utječu na nezaposlenost kroz stvaranje pritiska sindikata na pregovaranje o nadnicama. S druge strane, plaće u javnom sektoru financiraju se putem poreza. Konkretnije, empirijski dokazi upu- 
ćuju na to da je kreiranje jednog javnog radnog mjesta uništilo oko 1,5 privatnih radnih mjesta, smanjeno je sudjelovanje na tržištu rada i na kraju je povećan broj nezaposlenih radnika za 0,3 .

Navedena literatura sugerira da je povezanost između državnih rashoda, čija su sastavnica naknade za plaće u javnom sektoru, i ekonomskog rasta negativna. Iako su pojedina empirijska istraživanja (Callan et al., 2010., Caponi, 2017.) pokazala suprotno, većina provedenih istraživanja ukazuje na to veći državni rashodi negativno utječu na ekonomski rast. Međutim, navedena tematika nije empirijski istražena u hrvatskoj literaturi. U ovome radu prvi puta je provedeno empirijsko istraživanje učinka javnih plaća na hrvatsko gospodarstvo.

Tablica 1:

PREGLED RELEVANTNIH EMPIRIJSKIH ISTRAŽIVANJA

\begin{tabular}{|l|l|l|l|c|}
\hline \multicolumn{1}{|c|}{$\begin{array}{c}\text { Autor(i) i go- } \\
\text { dina }\end{array}$} & Model/pristup & \multicolumn{1}{|c|}{ Korištene varijable } & Razdoblje & Zemlja/e \\
\hline $\begin{array}{l}\text { Trošt i Bojnec } \\
\text { (2015.) }\end{array}$ & $\begin{array}{l}\text { Johansenov } \\
\text { pristup } \\
\text { kointegraciji }\end{array}$ & $\begin{array}{l}\text { BDP, izvoz dobara i usluga, } \\
\text { rashodi za plaće u javnom } \\
\text { sektoru }\end{array}$ & 2001.-2014. & Slovenija \\
\hline $\begin{array}{l}\text { Hernández de } \\
\text { Cos i Moral- } \\
\text { Benito (2014.) }\end{array}$ & $\begin{array}{l}\text { Bayesova teorija } \\
\text { odlučivanja i } \\
\text { Panel model } \\
\text { regresije }\end{array}$ & $\begin{array}{l}\text { Fiskalna konsolidacija, rashodi } \\
\text { za plaće u javnom sektoru, } \\
\text { aktivnost privatnog sektora }\end{array}$ & 1980.-2007. & $\begin{array}{l}\text { 21 zemlja } \\
\text { OECD-a }\end{array}$ \\
\hline $\begin{array}{l}\text { Callan et al. } \\
\text { (2010.) }\end{array}$ & $\begin{array}{l}\text { Model simulacije } \\
\text { učinka poreza }\end{array}$ & $\begin{array}{l}\text { Plaće u javnom sektoru, porez, } \\
\text { ekonomski rast }\end{array}$ & 1994.-2011. & Irska \\
\hline $\begin{array}{l}\text { Holm-Hadulla } \\
\text { et al. (2010.) }\end{array}$ & VAR model & $\begin{array}{l}\text { Rashodi za plaće u javnom } \\
\text { sektoru, konkurentnost, } \\
\text { makroekonomska stabilnost, } \\
\text { plaće u privatnom sektoru }\end{array}$ & 1970.-2008. & $\begin{array}{l}\text { Zemlje } \\
\text { eurozone }\end{array}$ \\
\hline $\begin{array}{l}\text { Afonso i } \\
\text { Gomes (2010.) }\end{array}$ & $\begin{array}{l}\text { Model ravnoteže } \\
\text { tržišta rada }\end{array}$ & $\begin{array}{l}\text { Plaće u javnom sektoru, plaće u } \\
\text { privatnom sektoru, zaposlenost }\end{array}$ & 1974.-2006. & $\begin{array}{l}\text { Zemlje } \\
\text { OECD-a }\end{array}$ \\
\hline $\begin{array}{l}\text { Ardagna } \\
\text { (2004.) }\end{array}$ & IS-LM model & $\begin{array}{l}\text { Kamatne stope, fiskalna pozicija } \\
\text { zemlje (ekonomski rast), fiskalna } \\
\text { politika, cijene dionica, deficit }\end{array}$ & 1960.-2002. & $\begin{array}{l}\text { Zemlje } \\
\text { OECD-a }\end{array}$ \\
\hline $\begin{array}{l}\text { Algan et al. } \\
\text { (2001.) }\end{array}$ & $\begin{array}{l}\text { Model ravnoteže } \\
\text { tržišta rada }\end{array}$ & $\begin{array}{l}\text { Zaposlenost u javnom sektoru, } \\
\text { zaposlenost u privatnom } \\
\text { sektoru, stopa participacije }\end{array}$ & 1960.-2000. & $\begin{array}{l}\text { 17 zemalja } \\
\text { OECD-a }\end{array}$ \\
\hline $\begin{array}{l}\text { Alesina i } \\
\text { Ardagna (1998.) }\end{array}$ & Studija slučaja & $\begin{array}{l}\text { Fiskalna politika, primarni } \\
\text { saldo, kamatne stope }\end{array}$ & 1960.- 1994. & $\begin{array}{l}\text { Zemlje } \\
\text { OECD-a }\end{array}$ \\
\hline
\end{tabular}




\section{Empirijska analiza učinka javnih plaća na ekonomska kretanja u Republici Hrvatskoj}

\subsection{Podaci i model}

Pri provođenju kointegracijske analize koriste se mjesečni podaci o plaćama u javnom sektoru i ekonomskoj aktivnosti. Budući da ne postoje mjesečni podaci o bruto domaćem proizvodu, kao aproksimacija je korišten realni indeks industrijske proizvodnje koji je deflacioniran indeksom potrošačkih cijena (CPI), 2010.=100. Budući da se podaci o bruto domaćem proizvodu objavljuju tromjesečno, a indeksi industrijske proizvodnje mjesečno, takva aproksimacija često je korištena u ekonometrijskim istraživanjima s ciljem očuvanja stupnjeva slobode i pouzdanosti rezultata analize. Pri ispitivanju učinka indirektnog poreza na ekonomsku aktivnost u Hrvatskoj takvu aproksimaciju koriste Palić et al. (2017). Plaće u javnom sektoru određene su prema NACE statističkoj klasifikaciji gospodarskih aktivnosti u Europskoj zajednici (Eurostat, 2008.). Prosjek place za kategorije O (javna uprava i obrana), P (obrazovanje) i Q (zdravstvo i socijalne djelatnosti) na mjesečnoj razini koristi se kao aproksimacija plaća u javnom sektoru.

Kako bi se eliminirao problem heteroskedastičnosti, što je u radu ispitano nakon procjene modela, spomenute varijable analizirane su u logaritamskim vrijednostima. Prema tome, varijable uključene u analizu su logaritamske vrijednosti realnog indeksa industrijske proizvodnje $Y$ i logaritamske vrijednosti plaća u javnom sektoru $W$ od siječnja 2000. do veljače 2017. godine.

Za ispitivanje stacionarnosti varijabli, prije provođenja Johansenovog postupka, za odabrane varijable proveden je prošireni Dickey-Fullerov test (engl. Augmented Dickey Fuller test, ADF test). Rezultati ADF testa dani su u Tablici 2. Obje varijable su nestacionarne u razinama, te stacionarne u prvim diferencijama uz $5 \%$, odnosno $10 \%$ signifikantnosti ${ }^{1}$.

${ }^{1}$ Varijabla LY je nestacionarna u prvim diferencijama samo uz konstantu i trend. Međutim, $\mathrm{s}$ obzirom na to da niz indeksa industrijske proizvodnje ne pokazuje postojanje trend komponente temeljem grafičkog prikaza, u obzir nisu su uzeti rezultati ADF testa za varijablu $\Delta \mathrm{LY}$ uz trend. 
Tablica 2:

\section{ADF T- TEST VELIČINE ZA ODABRANE VARIJABLE U RAZINAMA I PRVIM DIFERENCIJAMA}

\begin{tabular}{|c|c|c|c|}
\hline Varijabla & Konstanta & Konstanta i trend & Bez determinističkih komponenata \\
\hline $\mathrm{Y}$ & $-1,1044$ & $-1,8007$ & $-0,2839$ \\
\hline$\Delta \mathrm{Y}$ & $-2,7663^{*}$ & $-2,7208$ & $-2,7704^{*}$ \\
\hline $\mathrm{W}$ & $-0,4599$ & $-1,6503$ & 2,2472 \\
\hline$\Delta \mathrm{W}$ & $-3,6674^{*}$ & $-3,5932^{* *}$ & $-2,8659^{*}$ \\
\hline
\end{tabular}

Izvor: Izračun autora, * označava stacionarnost vremenskog niza uz 5\% značajnosti, **označava stacionarnost vremenskog niza uz $10 \%$ značajnosti

Prema Enders (2015.), ako je linearna kombinacija nestacionarnih varijabli stacionarna, među varijablama postoji dugoročna povezanost. Pritom se pojam „dugoročna ravnoteža“ u ekonometrijskom smislu koristi različito u odnosu na to kako taj pojam koriste ekonomski teoretičari. Ekonomski teoretičari koriste taj pojam u smislu jednakosti između stanja ekonomskih pojava. Međutim, ekonometrijskom smislu taj pojam se odnosi na dugoročnu povezanost nestacionarnih varijabli. Kointegracija ne zahtijeva da dugoročna ravnoteža bude rezultat tržišnog mehanizma ili ponašanja pojedinaca (Dumičić i Čibarić, 2010.). U nastavku je primjenom Johansenove procedure ispitano postojanje kointegracije.

\subsection{Ispitivanje postojanja kointegracije i analiza modela dugog roka}

Prije svega, potrebno je odabrati odgovarajući model koji se odnosi na postojanje determinističkih komponenti (trenda i konstante) u VEC modelu (Bahovec i Erjavec, 2009.). Odabran je model kod kojeg je konstanta prisutna u kointegracijskom prostoru, ali ne u VEC modelu.

Sljedeći korak je određivanje broja kointegracijskih relacija. Odluka o ishodu testova donosi se usporedbom empirijskih test veličina s kritičnim vrijednostima testa traga matrice i testa maksimalne svojstvene vrijednosti. Kod oba navedena testa testiranje se provodi sve dok se prvi puta ne može odbaciti nulta hipoteza. Oba testa upućuju na to da je broj kointegracijskih relacija jednak jedan uz 5\% značajnosti što je vidljivo iz Tablice 3. 
Tablica 3:

REZULTATI TESTA TRAGA MATRICE I TESTA MAKSIMALNE
SVOJSTVENE VRIJEDNOSTI

\begin{tabular}{|c|c|c|c|c|c|}
\hline $\begin{array}{c}\text { Broj } \\
\text { kontegracijskih } \\
\text { relacija }\end{array}$ & $\begin{array}{c}\text { Svojstvena } \\
\text { vrijednost }\end{array}$ & $\begin{array}{c}\text { Test traga } \\
\text { matrice }\end{array}$ & $\begin{array}{c}\text { Kritična } \\
\text { vrijednost } \\
\text { (test traga } \\
\text { matrice) }\end{array}$ & $\begin{array}{c}\text { Test } \\
\text { maksimalne } \\
\text { svojstvene } \\
\text { vrijednosti }\end{array}$ & $\begin{array}{c}\text { Kritična vrijednost } \\
\text { (test maksimalne } \\
\text { svojstvene } \\
\text { vrijednosti) }\end{array}$ \\
\hline 0 & 0,091509 & $24,00470^{*}$ & 20,26184 & $18,13841^{*}$ & 15,89210 \\
\hline 1 & 0,030562 & 5,866289 & 9,164546 & 5,866289 & 9,164546 \\
\hline
\end{tabular}

Izvor: Izračun autora, * označava odbacivanje nulte hipoteze na razini signifikantnosti 5\%

Odabran je model u kojem konstanta postoji u dugoročnom modelu (kointegracijska jednadžba), ali ne i u kratkom roku. Na temelju kointegracijskog vektora procijenjena je jednadžba dugog roka s pripadajućom $t$-vrijednosti u zagradi:

$$
\hat{Y}=9,695-0,589 \mathrm{~W}
$$$$
(-3,782)
$$

Član korekcije pogreške (engl. error correction term, ECT) dobiven na temelju jednadžbe iznosi -0,1039, što znači da se u svakom mjesecu korigira 10,39\% neravnoteže u varijabli $Y$. Negativan predznak daje informaciju o povratku varijabli u ravnotežno stanje, a iznos ukazuje na brzinu povratka u ravnotežno stanje. Prema tome, varijable bi se trebale vratiti u ravnotežno stanje za približno 10 mjeseci.

Kako bi se ispitala adekvatnost procijenjenog VEC modela, proveden je Whiteov test heteroskedastičnosti grešaka relacije. Test veličina Whiteovog testa $\chi^{2}$ iznosi 220,7234, s pripadajućom empirijskom razinom signifikantnosti 0,1284. Stoga se ne može odbaciti nulta hipoteza o homoskedastičnosti uz $1 \%$ signifikantnosti. Nadalje, proveden je LM test autokorelacije grešaka relacije, te se na razini značajnosti 5\% ne može odbaciti nulta hipoteza o nepostojanju autokorelacije greška relacije do pomaka 12, budući da su sve pripadne empirijske razine signifikantnosti uz test veličine veće od 0,05 .

Sljedeći korak je ispitivanje stabilnosti modela korelacije pogreške izračunom inverznih korijena karakterističnog AR polinoma. Procijenjeni model s $r$ kointegracijskih relacija je stabilan ako je $k-r$ parametara karakterističnog kruga jednako jedan, a ostali parametri imaju modul manji od jedan i leže unutar jediničnog kruga. Pritom je $r$ broj kointegracijskih relacija, a $k$ broj endogenih 
varijabli. Primjenom programa EViews 8 izračunati su inverzni korijeni karakterističnog AR polinoma za procijenjeni VEC model. Provedena analiza je pokazala da postoji 1 jedinični korijen, a ostali korijeni imaju modul manji od jedan. S obzirom na to da je model procijenjen s dvije varijable, te je utvrđeno postojanje jedne kointegracijske relacije, model s jednim jediničnim korijenom je stabilan.

Rezultati provedene empirijske analize potvrđuju pretpostavku da plaće u javnom sektoru imaju statistički signifikantan negativan učinak na ekonomsku aktivnost u dugom roku. Stoga, što su plaće u javnom sektoru veće, rashodi države su veći, čime dolazi do rasta proračunskog deficita. Uslijed znatno povećanog deficita, dolazi do visokog javnog duga koji prema teoriji javnih financija može dovesti do nestabilnosti te sporijeg oporavka zemalja u kontekstu smanjenja javnog duga. Kolačević i Hreljac (2011.) naglašavaju da je vrlo važno razlikovati proračunski deficit i javni dug, odnosno deficit kao tijek, a javni dug kao stanje, kumulativ dosadašnjih proračunskih deficita. Pokušavaju odrediti optimalnu granicu zaduženja, odnosno onu granicu koja neće negativno utjecati na gospodarski rast i dovesti državu u stanje financijske nesolventnosti i nestabilnosti. No, zaključuju da ne postoji neki jasan i općeprihvaćeni kriterij određivanja te granice, prvenstveno radi opće razlike između zemalja, jer su neke zemlje u usponu, a druge se suočavaju sa unutarnjim i vanjskim problemima. Ukazuju na to da na politiku zaduženja najveći utjecaj ima Europska unija, odnosno kriteriji konvergencije za ulazak u Europsku monetarnu uniju.

Naposljetku, pri interpretaciji rezultata provedene analize, vrlo je zanimljivo uzeti u obzir percepciju hrvatskih građana o javnom sektoru. Na uzorku od 502 građana, Ekonomski institut, Zagreb (2014.) proveo je terensko anketno istraživanje gdje su se između ostaloga propitivali stavovi hrvatskih građana o javnom sektoru. Prema rezultatima istraživanja, građani najviše zamjeraju javnom sektoru neučinkovitost, ali prevladava i mišljenje da je javni sektor preskup i prevelik, te da je porezno opterećenje preveliko, što ukazuje na to da je postojeće porezno opterećenje izravno određeno veličinom javnog sektora, ali i neizravno njegovom učinkovitošću. Spomenuta percepcija hrvatskih građana sukladna je zaključcima u radovima Nestić et al. (2014.) te Matošec i Globan (2016.). Prema Nestić et al. (2014.), u razdoblju krize, od 2008. do 2012. udio zaposlenih u Hrvatskom javnom sektoru je povećan. U spomenutom razdoblju ,neprilagođeni“ jaz (ne uzima se u obzir obrazovna struktura) između javnih i privatnih plaća povećavao se u korist plaća u javnom sektoru.

No, budući da smanjenje rashoda opće države nije jedini način obuzdavanja javnih financija, države se češće okreću poreznoj politici odnosno dodatnim poreznim opterećenjima. Matošec i Globan (2016.) s tog aspekta smatraju da rješavanju dužničke krize treba pristupiti poticanjem ekonomskog rasta, a ne kratkoročnim punjenjima proračuna. U tom kontekstu, Šimović et al. (2014.) pomoću empirijske 
analize zaključuju da direktni porezi, posebno porez na dohodak i doprinosi, imaju dugotrajno negativan i snažan učinak na kretanje BDP-a u Hrvatskoj, dok pozitivne učinke indirektnih poreza treba promatrati s dozom opreza. Također, Palić et al. (2017.) empirijski potvrđuju kako porez na dohodak u Hrvatskoj ima signifikantan negativan učinak na ekonomski rast u dugom roku. Na temelju provedene analize i prethodnih istraživanja, preporuka nositeljima fiskalne politike je provoditi fiskalnu konsolidaciju više putem smanjenja javnih rashoda, a manje porastom poreznog opterećenja. U tom kontekstu javne plaće trebaju biti prilagođene gospodarskim okolnostima kako bi se osigurao stabilan rast.

\section{ZAKLJUČAK}

U radu je primjenom Johansenovog pristupa kointegraciji ispitan učinak javnih plaća na ekonomska kretanja u Hrvatskoj u razdoblju od siječnja 2000. do veljače 2017. godine. Analizom se pokušalo odgovoriti na pitanje: Imaju li plaće u javnom sektoru i kakav učinak na ekonomska kretanja? Gotovo sve zemlje zahvaćene recentnom ekonomskom krizom bile su uključene u postupak prekomjernog deficita, pa tako i Hrvatska. Zahvaljujući znatnim naporima koji su uglavnom bili usmjereni restrukturiranju javnog sektora, budžetski su deficiti uglavnom dovedeni pod kontrolu. Danas najznačajnija prepreka Hrvatskoj u sudjelovanju u Europskoj monetarnoj uniji ostaje javni dug. Kako bi se javni dug smanjio nije samo dovoljno poticati prihodovnu stranu, odnosno nametati dodatna porezna opterećenja, već je ključno smanjiti rashode, a dio tih rashoda su i plaće u javnom sektoru, koje prema rezultatima ovog istraživanja dovode do smanjene ekonomske aktivnosti. Nositeljima ekonomske politike bitan je nalaz provedenog istraživanja, s obzirom da je donošenje odluka o strukturi javnih rashoda jedan od najvažnijih elemenata vođenja fiskalne politike. Uslijed visokog javnog duga i kamata u Hrvatskoj, adekvatna struktura javnih rashoda još više dobiva na značaju. Prema tome, javne plaće kao važan dio proračunskih rashoda trebaju biti prilagođene gospodarskim okolnostima s ciljem postizanja stabilnog rasta.

\section{Literatura:}

Afonso A. i Gomes P. (2010.). "Interactions between private and public sector wages", Institute for the Study Labor (IZA) Discussion Paper Series, No. 5322.

Alesina A. i Ardagna S. (1998.). "Tales of Fiscal Adjustments", Economic Policy 13(27): 489-585. 
Algan Y., Cahuc P. i Zylberberg A. (2001.). "Public Employment and Labor Market Performances", 34th Panel Meeting of Economic Policy in Brussels.

Ardagna S. (2004.). "Financial markets' behavior around episodes of large changes in the fiscal stance", European Central Bank: Working Paper Series No. 390.

Bahovec V. i Erjavec N. (2009.). “Uvod u ekonometrijsku analizu”. Zagreb: Element.

Callan T., Nolan B. i Walsh J. (2010.). "The Economic Crisis, Public Sector Pay, and the Income Distribution", Institute for the Study of Labor (IZA), Discussion Paper No. 4948, Bonn.

Caponi, V. (2017.). The effects of public sector employment on the economy. IZA World of Labor, 332, DOI: 10.15185/izawol.332.

Dumičić K. i Čibarić, I. (2010.).,,The Analysis of Household Savings in Republic of Croatia Using Cointegration Approach", The American Business Review, (15), 1: 220-226.

Ekonomski institut, Zagreb (2014.). „Kako pobuditi rast hrvatskog gospodarstva“, Klub Ekonomskog instituta, Zagreb, www.eizg.hr [12.7.2017]

Eurostat (2008.). "Statistical Classification of Economic Activities in the European Community, Rev. 2 “, Dostupno na: http://ec.europa.eu/eurostat/ramon/nomenclatures/index.cfm?TargetUrl=LST_NOM_DTL\&StrNom=NACE_REV2\&StrLangua geCode $=\mathrm{EN}[10.8 .2017]$.

Galì, J. (2008.). „Monetary Policy, Inflation and Business Cycle: An Introduction to the New Keynesian Framework“, Princeton University Press.

Herath, S. (2010.). "The size of the government and economic growth: An empirical study of Sri Lanka", Institute for Regional Development and Environment Vienna, Austria: University of Economics and Business.

Hernández de Cos P. i Moral-Benito, E. (2014.). “The Role of Public Wages in Fiscal Consolidation Processes", European Commission. Dostupno na: http://ec.europa. eu/economy_finance/events/2013/20131211_ecfin_workshop/pdf/the_role_of_public_wages_in_fiscal_consolidation_processes_en.pdf [10. srpnja 2017].

Holm-Hadulla F., Kamath K., Lamo A., J. Pérez J. i Schuknecht L. (2010.). "Public wage in the euro area towards securing stability and competitiveness", European Central Bank: Occasional Paper series, No. 112.

Kolačević S. i Hreljac B. (2011.). „Javni dug kao ključna varijabla ostvarenja ciljeva ekonomske politike“, Ekonomski pregled, (62), 3-4: 208-229.

Matošec M. i Globan T. (2016.). „Public Debt-to-GDP Ratio in New EU Member States: Cutthe Numerator or Increase the Denominator?“, Journal for Economic Forecasting, 19, 3, 2016.

Nestić D., Rubil I. i Tomić I. (2014.). „Analiza plaća u javnom i privatnom sektoru u Hrvatskoj“, Ekonomski institut Zagreb.

Palić, I., Žmuk, B., Grofelnik, B. (2017.). „The long-run impact of personal income taxation on economic development: Evidence from Croatia“, Croatian Review of Economic, Business and Social Statistics, (3), 1: 35-44. 
Pascual Sáez, M., Alvarez-García, S. i Castañeda, D. (2017.). "Government expenditure and economic growth in the European Union countries: New evidence".

Rodseth, A. (2000.). „Open economy macroeconomics“, Cambridge University Press.

Sever I., Drezgić S. i Blažić H. (2011.). "Budget spending and economic growth in Croatia - Dynamics and relationships over the past two decades", Hrčak (29), 2:291-331.

Šimović H., Ćorić T. i Deskar-Škrbić (2015.). „Mogućnosti i ograničenja fiskalne politike u Hrvatskoj“, Ekonomski pregled, (65), 6: 541-575.

Trošt, M. i Bojnec, Š. (2015.). „Causality between public wage bill, exports and economic growth in Slovenia", Economic Research - Ekonomska Istraživanja, (28), 1:119-131, DOI: 10.1080/1331677X.2015.1028241.

Zimčík, P. (2016.). "Economic Growth and budget constraints: EU countries panel dana analysis“.

\title{
LONG-RUN ANALYSIS OF THE IMPACT OF PUBLIC SECTOR WAGES ON ECONOMIC ACTIVITY IN CROATIA
}

\begin{abstract}
Public sector wages are an important part of the government budget and a significant element of conducting fiscal policy. The purpose of this research is to empirically assess how public sector wages affect economic activity in small open economy, using Croatia as the representative small open economy. In line with the results of previous empirical research, a research hypothesis according to which the increase in public wages in Croatia leads to a decrease in economic activity has been stated. In the central part of the paper, the long-run effect of public wages on economic trends in Croatia is examined by employing Johansen cointegration approach, using monthly data on public sector wages and industrial production indices from January 2000 to February 2017. The results of the conducted research suggest that an increase in public wages in the long-run causes a decrease in economic activity in Croatia, which is in line with previous research in international literature. The results of the research point to the need of fiscal consolidation implementation to a greater extent through the reduction of public expenditure, which includes public wages, and less through an increase in tax burden.
\end{abstract}

Key words: public sector wages, economic trends, error correction model, Johansen's approach to cointegration, small open economy 